\title{
Correspondence
}

\section{The use of capnography for apnea \\ monitoring during non-invasive \\ positive pressure ventilation during \\ spinal anesthesia}

To the Editor:

Non-invasive positive pressure ventilation (NPPV) has become increasingly common, ${ }^{1}$ and we recognize that patients requiring NPPV devices present several unique challenges when they require anesthesia and surgery. ${ }^{2}$ One particular challenge is respiratory monitoring. We share our positive experience using capnography as an apnea monitor during NPPV in a sedated patient with chronic obstructive pulmonary disease undergoing spinal anesthesia. The patient was a 69 -yr-old female who was scheduled for replacement of her right femoral head for a fracture sustained during hospital admission prompted by an exacerbation of her chronic obstructive pulmonary disease. During this admission, her attending physician prescribed a portable NPPV ventilator (NIP Nasal III ${ }^{\mathrm{TM}}$, Teijin Inc., Tokyo, Japan) and she was successfully treated using bi-level positive pressure ventilation $\left(\mathrm{O}_{2}\right.$ at $5 \mathrm{~L} \cdot \mathrm{min}^{-1}$, inspiratory positive airway pressure $14.5 \mathrm{~cm} \mathrm{H}_{2} \mathrm{O}$, expiratory positive airway pressure $4.0 \mathrm{~cm} \mathrm{H}_{2} \mathrm{O}$, backup respiratory rate $11 \mathrm{~min}^{-1}$ ) immediately before surgery. During spinal anesthesia, she was lightly sedated (bispectral index $=70$ to 80 ) using a continuous intravenous infusion of propofol. To monitor for apnea during sedation, we attached a sampling tube of the capnograph to the nasal mask used for NPPV (Figure, panel A) and successfully obtained a reliable capnograph trace throughout anesthesia (Figure, panel B). We advocate this simple approach for capnography to detect apneic events during NPPV.

Hiroyuki Kinoshita MD PhD*

Naoyuki Matsuda MD phD $†$

Yoshio Hatano MD PhD*

Wakayama Medical University, ${ }^{*}$ Wakayama; Toyama University School of Medicine, $†$ Toyama, Japan E-mail: hkinoshi@pd5.so-net.ne.jp

Accepted for publication June 8, 2007.

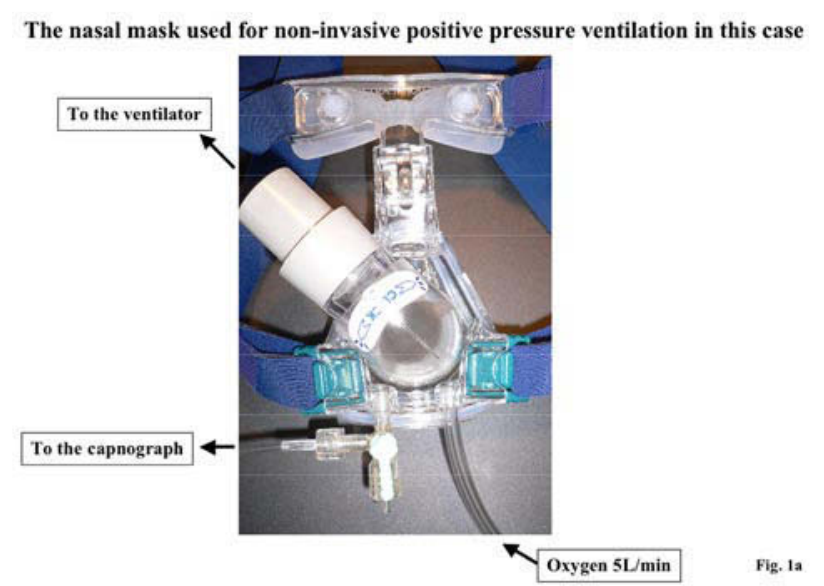

Capnogram during non-invasive positive pressure ventilation in this case

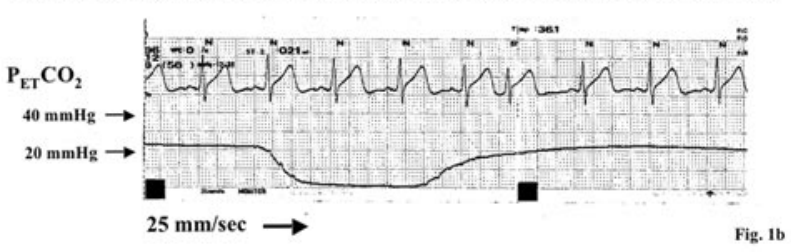

FIGURE Panel $A$ ) The non-invasive positive pressure ventilation system showing the capnograph sampling tube attached to the nasal mask via a pressure monitoring port. Panel B) Representative capnograph tracing demonstrates good signal quality.

\section{References}

1 Lloyd-Owen SJ, Donaldson GC, Ambrosino N, et al. Patterns of home mechanical ventilation use in Europe: results from Eurovent survey. Eur Respir J 2005; 25: 1025-31.

2 Bapat PP, Anderson JA, Bapat S, Sule A. Use of continuous positive airway pressure during spinal anaesthesia in a patient with severe chronic obstructive pulmonary disease. Anaesthesia 2006; 61: 1001-3. 